\title{
"DATA", PARADIGMA DE LA SOCIEDAD CIBERNÉTICA
}

\author{
Humberto FÉLIx RuANI*
}

\begin{abstract}
Resumen
El objetivo de este trabajo, consiste en un análisis del dato (data) o información, como bien tutelado por la sociedad cibernética.

Toda sociedad, se construye con usos, costumbres, valores, que para sus miembros constituyen bienes a tutelar. Estos bienes no son absolutos, y van mutando con el transcurso del tiempo. Algunos de ellos por su importancia y trascendencia se constituyen en paradigmas principales de la sociedad correspondiente. A partir de mediados del siglo pasado, se generó una nueva forma de procesar la información (ordenadores), con un idioma especial (binario), que permite el tratamiento de la información (sistemas) en una forma compleja y distinta a la tradicional. A estas altas tecnologías se añadieron disparadores comunicacionales (internet), que mutó el valor de la información a nivel mundial, y lo constituyó en su paradigma principal.
\end{abstract}

Palabras clave: Derecho informático, Data, Bien jurídico, Paradigma cibernético

\begin{abstract}
The objective of this work, is to make an analysis of the data (dates) or information, like a right protected by the cybernetic society.

All society is constructed with uses, customs and values which are importants assets to their citizens, so they must protect them. These, rights, assets are not absolute, and are changing with the course of time. Some of them because of their importance and transcendence are constituted in main paradigms of the corresponding society. From half-full of the last century, a new form to process the information (computers) has been generated, with a special language (binary), that allows the data processing (systems) in a complex and different form from the traditional one. To these high teches, communicational triggers were added (Internet), that changed the value of the information at world-wide level, and constituted them in its main paradigm.
\end{abstract}

Key words: Informatics \& law - Dates - Protected rights - Cybernetic paradigm.

\section{Sumario}

1. Introducción. 2. Acepciones terminológicas. 2.1. Dato. 2.2. Data. 2.3. Paradigma. 2.4. Cibernética. 2.5. Sociedad cibernética. 3. Problemática. 4. Propuestas. 5. Conclusiones.

\footnotetext{
* Miembro del Instituto de Derecho Informático del Colegio de Abogados de la Ciudad de Buenos Aires. Presidente de la Asociación Argentina de Informática Jurídica A.A.I.J. (Asociación coorganizadora del XV Congreso Iberoamericano de Derecho e Informática -F.I.A.D.I. - Argentina 2011).
} 


\section{INTRODUCCIÓN}

El objetivo de este trabajo, no pretende por su extensión dar una visión profunda ni completa de la cuestión a desarrollar, se orienta principalmente a analizar los efectos que producen en las sociedades y los ordenamientos jurídicos, las nuevas tecnologías, en particular los ordenadores, sistemas de software, medios comunicacionales como internet.

Un cotejo retrospectivo nos permite observar que las distintas sociedades han atravesado en el devenir del tiempo y de las distintas latitudes geográficas, numerosos procesos de cambio originados en invenciones del hombre, a partir de los cuales, las sociedades vieron alteradas su concepción valorativa, y consecuentemente los juristas debimos adecuar las técnicas legislativa para tutelar estos nuevos bienes sociales que las innovaciones tecnológicas generaron.

Invenciones como la imprenta, la electricidad, el teléfono, los automotores, etc., revolucionaron en su tiempo los usos y costumbres de los individuos y de la sociedad misma, generaron necesidades de regulaciones jurídicas que protegieran los derechos afectados. Estos cambios sociales se producían en periodos más o menos prolongados y en espacios geográficos limitados, hasta alcanzar con el tiempo y según su importancia una dimensión global, todo ello permitía a las sociedades, una adaptación medianamente progresiva y ordenada, y a los sistemas jurídicos irse adecuando al tratamiento de estos acontecimientos.

A mediados del siglo $\mathrm{XX}$, emerge la posibilidad tecnológica de procesar los datos o información con ordenadores, estos equipos procesan la información con una velocidad y modalidad que no era posible hasta ese entonces.

También surgen nuevas y novedosas tecnologías de comunicación social, satélites, telefonía celular, internet, que combinadas con computadores, sistemas informáticos y telemáticos, generan una mezcla explosiva, que no permite a las sociedades adaptarse a la velocidad en que se propagan, ni a los sistemas jurídicos responder con un plexo normativo eficaz y oportuno.

Por ello analizaremos más adelante cuáles son los principales problemas que generan (problemática) y qué modos de tratamiento podrían ser oportunos (propuestas), para la mejor adaptación social y jurídica al cambio. 
Hecha la aclaración, pasaremos a considerar distintas acepciones terminológicas, con la finalidad de una adecuada interpretación del contenido de este artículo.

\section{ACEPCIONES TERMINOLÓGICAS}

\subsection{Dato}

(Del latín datum), es una representación simbólica (numérica, alfabética, algorítmica etc.), atributo o característica de una entidad. El dato no tiene valor semántico (sentido) en sí mismo, pero convenientemente tratado (procesado) se puede utilizar en la realización de cálculos o toma de decisiones. Es de empleo muy común en el ámbito informático.

\subsection{Data}

Acepción de origen latino, es tomada en este trabajo con el alcance mencionado en la terminología dato, o como bien lo sugiere la figura jurídica habeas data cuando se define como la acción constitucional o legal que tiene cualquier persona que figura en un registro o banco de datos, de acceder a tal. En otros términos, comprende todo tipo de dato o información, susceptible de ser incorporada en un ordenador y a su procesamiento, lo que le otorga un valor adicional al contenido original del elemento ingresado.

\subsection{Paradigma}

Se trata de un vocablo que ha sido definido de muchas formas, tenemos acepciones etimológicas, psicológicas, vulgares, y de las ciencias sociales, entre otras muchas más.

Por tal motivo he descartado al análisis las primeras conceptualizaciones y optado por la última, es decir, desarrollaremos la concepción de paradigma en el ámbito de las ciencias sociales.

Dentro de este marco referencial, es sumamente ilustrativa la definición de Kuhn, a la cual me adhiero, cuando en la modificación a su obra (año 1969), define el término paradigma como "una completa constelación de creencias, valores y técnicas, compartidas por los miembros de una determinada comunidad". Esta definición no tiene desperdicio, ya que cuando dice una determinada comunidad, no puede ser interpretado de otra manera que aquella que tiene una fijación temporal, además de geográfica. Debo destacar que esta 
definición de paradigma, no es aceptada pacíficamente por muchos calificados doctrinarios, pero a los efectos de la interpretación del presente artículo resulta conveniente aceptarla.

\subsection{Cibernética}

El término cibernética también tiene múltiples acepciones, pero a los efectos de este trabajo, tomaré algunas características descriptas por Gregory Bateson y otras de Stafford Beer.

Gregory Bateson, afirma que la cibernética es "el más grande mordisco a la fruta del árbol del conocimiento que la humanidad haya dado en los últimos 2000 años".

Stafford Beer, define a la cibernética como "la ciencia de la organización efectiva".

En otro orden de ideas y siguiendo en parte a los autores mencionados, podemos manifestar que la cibernética es una ciencia interdisciplinaria, que estudia los flujos de información que rodean un sistema, y la forma en que esta información es usada por el sistema como un valor que le permite controlarse a sí mismo.

Interesa resaltar de esta disciplina, entre sus múltiples objetivos de estudio que se destaca el de los computadores y el de los lenguajes formales de la ciencia.

Podemos decir entonces, que la cibernética se refiere a la concepción de un vocablo que apunta al abarcamiento de una porción muy importante del conocimiento de la humanidad, y lo organiza científicamente en forma efectiva, con estrecha vinculación a la órbita de las computadoras y los lenguajes formales de la ciencia.

\subsection{Sociedad cibernética}

Al referirme a la sociedad cibernética, me dirijo a una sociedad de actualidad, donde la tecnología, irrumpe con una velocidad y amplitud globalizada, que se caracteriza por la extraterritorialidad e inmediatez en la transmisión de las informaciones, que a su vez son elaboradas por sistemas informáticos que las acopian, procesan y organizan, para luego proceder a su difusión con la mas alta tecnología comunicacional. 
En esta sociedad la información o dato, adquiere un valor y proporción, que se destaca de todos los demás, a tal punto de ser el referente de una forma de vida, que tiene vocación universal o globalizante, que le constituye en un bien jurídicamente tutelable, y justamente las dificultades en el tutelaje del referido bien jurídico son materia del desarrollo del próximo ítem a tratar.

\section{PROBLEMÁTICA}

Como señalamos ut supra, los datos, o data, en la sociedad cibernética, reviste un valor extraordinario, desde el punto de vista económico, político, social, cultural, y en general desde cualquier aspecto, ya que además de ser un medio de comunicación, es un factor de poder, capaz de modificar los valores mas intrínsecos de una sociedad.

Estos cambios pueden ser deseados o no por el cuerpo social, dirigidos a reforzar las costumbres o hábitos o en dirección opuesta, tendientes a reforzar la tutela de bienes jurídicos tradicionales, o todo lo contrario, también puede ser la información utilizada almacenada o direccionada con fines constructivos o destructivos. En definitiva puede alterar en cualquier sentido los valores que una sociedad detente en un tiempo determinado.

Los datos que contiene un ordenador, pueden ser aplicados a la celebración de contratos tradicionales o a distancia, en particular desde la aceptación generalizada de la firma digital, a su vez según el contenido del contrato, puede ser del interés de los fueros civiles, comerciales o laborales como así también administrativos, sin excluir al penal, que siempre estará atento cuando la conducta de quienes trafiquen con los datos ingresen a los dominios de algún tipo penal. No resultará ajeno a estas cuestiones el derecho procesal, ya que este tipo de circunstancias se han incorporado definitivamente en forma expresa o tácita en los códigos de procedimientos de los Estados y también de los organismos supranacionales.

Como es dable observar, hay una íntima relación entre el dato cibernético y los aspectos jurídicos de los más variados fueros en el orden nacional e internacional, por lo que el derecho no puede permanecer ajeno a la evolución que el dato tenga en la sociedad.

Los datos pueden ser almacenados y procesados en un lugar del planeta y transferidos telemáticamente a otro, donde podría producir efectos jurídicos, estas características podemos definirlas dentro de los conceptos de inmediatez 
y extraterritorialidad, elementos estos que intentaremos desarrollar más adelante.

Con relación a la inmediatez y la extraterritorialidad, debemos considerar que a la velocidad de transmisión hay que agregar la posible diseminación del dato. Solo con pensar que en el planeta hay aproximadamente siete mil millones de potenciales usuarios de internet y que con relación a la competencia y extraterritorialidad hay aproximadamente 250 Estados independientes en la comunidad internacional, comprenderemos que estamos frente a un problema fenomenal, que crece día a día y que no responde a un gobierno único o específico, sino que está sujeto a múltiples regulaciones, locales, estaduales o de derecho internacional, de difícil armonización y mas difícil hermenéutica.

Sabemos que los datos pueden almacenarse en los ordenadores que los contienen, y constituir con ellos bancos de datos.

No se escapa al presente análisis, que los datos allí contenidos pueden ser utilizados de muy distintas maneras, en particular puede ser perjudicial para el derecho a la intimidad de las personas.

La información existente en los bancos de datos, puede ser tan variada como valiosa, el acceso a la misma puede ser abierto o cerrado, los contenidos pueden ser lícitos o ilícitos, y quien detente el poder de disposición de los mismos, puede constituirse en un aliado de los valores tradicionales de la sociedad o en un peligroso enemigo, capaz de ocasionar gravísimos daños simplemente con permitir que trasciendan los datos almacenados, o utilizarlos concretamente para perjudicar bienes o valores de terceros sensibles al contenido o información existente en los bancos de datos.

Pongamos el ejemplo de información reservada de siniestros de una compañía de aviación o de registro de pacientes que detentan enfermedades infecto contagiosas, como bien podría tratarse de información relacionada con la registración de inventos, de marcas o dominios. Los ejemplos dados son solo ilustrativos, porque el listado sería infinito; con el agravante, que por cada uno que enumeramos en ese período de tiempo seguramente surgirían varios para registrar.

También sabemos que los datos contenidos en un sistema informático, pueden estar sujetos a actos tendientes a su destrucción, saqueo o alteración, lo que nos conduce a los sistemas de seguridad, que si bien pueden ser paliativos 
para contrarrestar ese accionar en un determinado momento, la agilidad de los avances tecnológicos exigen una permanente actualización.

Otro tema de análisis es el lenguaje binario, que hace posible universalizar las distintos idiomas convencionales, que sumado a sistemas traductores, permiten en tiempos brevísimos, exterminar los limites idiomáticos.

También hay que señalar que al poder desarrollar el hombre actividades fuera de la orbita terrestre, lleva a esos ámbitos las inquietudes que nos ocupan, y por ende ese futuro ya ha comenzado y debemos prepararnos para enfrentar las novedosas problemáticas que le acompañan.

Por último, analizando el fenómeno de internet, todas estas cuestiones parecerían mínimas al compararse con el poder de ese gigante que convierte a quienes le ignoran en analfabetos cibernéticos, en atención a que quedan aislados de una nueva cultura, en la que se funden las distancias, con el espacio, y se borran los limites tradicionales entre presente pasado y futuro, dejando entre ellos un grisáceo velo donde cada vez es mas difícil distinguir las diferencias por la inmediatez que caracteriza el accionar cibernético.

\section{PROPUESTAS}

Habiendo analizado en el ítem anterior algunas de las problemáticas que se suscitan al tratarse este tema y a modo de síntesis, podemos colegir que el paradigma de la sociedad cibernética, esta integrado por dos elementos esenciales, uno que es su materia prima, "la información" (en sentido amplio, abarcativo de palabras imágenes, guarismos etc. que pueda ser sometido a ordenamiento en un computador).

El otro elemento imprescindible es "el ordenador" con sus accesorios y en particular todas las altas tecnologías que almacenan, procesan y transfieren los datos de que se trate. Téngase en cuenta que es una tecnología cambiante, y la velocidad en que se producen las innovaciones hace que la técnica de vanguardia utilizable durante la noche, se convierta en obsoleta al amanecer.

Entonces, la cuestión paradigmática se sustenta en esos dos elementos esenciales que son; 1 . La materia prima (la informacion) y 2. Los ordenadores, que convierten a la información incorporada, en un bien más valioso (data / datos), que es atesorable y temible a la vez - esto último cuando es utilizado en perjuicio de los valores éticos jurídicos de la sociedad cibernética. 
Esta última particularidad me motivó para intentar una propuesta que potencialice las razones de su atesoramiento y disuada a aquellos que pretenden utilizarlo en contra de los valores éticos jurídicos vigentes.

La primera característica de la propuesta es su carácter de integral, ya que debe fortalecer los aspectos positivos y combatir los negativos.

La mejor manera de lograr la integralidad mencionada es mediante su segunda caracterización consistente en la toma de conciencia de la problemática paradigmática de la sociedad cibernética.

Esa toma de conciencia no es atributo de un solo enfoque, ni acción, sino por el contrario debe desarrollarse con una perspectiva trialista, en cuanto amerita una perspectiva sociológica, otra dikelógica o valorativa y por ultimo la normológica.

Con relación al enfoque sociológico, creo que la toma de conciencia de la sociedad del valor de la información computarizada (data) y de los riesgos que implica el mal uso de esta materia prima, sería un paliativo importante para el tratamiento exitoso de la problemática en todo su conjunto, además habría que complementar esa toma de conciencia con una capacitación adecuada para interpretar el problema en toda su dimensión y facilitar de esa manera la colaboración espontánea de los elementos activos de la sociedad cibernética.

Por su parte, desde el punto de vista dikelógico, es perfectamente entendible que con la aplicación de las nuevas tecnologías el valor información o dato se incrementó en una manera extraordinaria, y por ende, siguiendo las reglas de la oferta y demanda, quien posea el control de la información o su disponibilidad, tiene en sus manos un bien deseado que goza del tutelaje jurídico si se obtuvo conforme a la normativa imperante.

Corresponde al Estado, arbitrar los medios para la protección de este preciado valor, en particular para establecer los vínculos con otros valores tutelados, y dar prioridades en cuanto a la urgencia que cada uno requiere al momento de reclamar protección o justicia.

Estos valores deben ser interaccionados y consensuados con los que la comunidad internacional privilegia, para evitar las dificultades de falta de armonización en posibles conflictos extraterritoriales. 
Desde el punto de vista normológico, debemos distinguir el plexo jurídico nacional, del internacional.

En el primero notaremos que - como siempre ha ocurrido - el derecho perseguirá a los hechos e intentará regularlos, haciendo uso del poder de coacción que caracteriza la aplicación del derecho en el área de soberanía estadual. Distinta será la situación cuando el conflicto tenga autoría o efectos que internacionalizan la problemática; allí deberá considerarse la relación entre los derechos de los Estados intervinientes, si existen tratados internacionales de cooperación, y si no los hay, tendremos que analizar si los procedimientos y el derecho de fondo de las naciones encartadas, pueden armonizarse para una solución consensuada o bien en última instancia quedarán los organismos internacionales o las Cortes de justicia que pudieran intervenir en las diferencias.

Es de destacar que los conflictos dominiales de Internet, pueden intentar resolverse por sistemas de resolución de conflictos, por árbitros, mediadores, etc. que son mecanismos muy convenientes. De cualquier manera, siempre la soberanía de los Estados puede hacer valer su potestad, con disposiciones que autoricen, rechacen o persigan a quienes intenten este tipo de posibles soluciones.

Otra propuesta interesante es que las autoridades de un país, proyecten o auspicien eventos internacionales, donde los académicos de distintas partes del mundo puedan presentar propuestas, para la lucha contra el flagelo del uso indebido de los datos, para defender la intimidad de las personas y también para combatir los delitos informáticos originados con el tráfico de información sensible.

Estas propuestas calificadas deberían ser distribuidas en los distintos Estados para análisis y conocimiento de las autoridades judiciales y legislativas, con la finalidad que cualquier proyecto de ley o sentencia, tenga a su alcance una valiosa doctrina argumental que refuerce la convicción de quienes tienen a su cargo decidir por sus respectivas sociedades [...].

Por ello eventos como el celebrado en Lima en noviembre de 2009, como el festejo del $25^{\circ}$ aniversario de la creación de la Federación Iberoamericana de Derecho Informático (FIADI), se convierte en un escenario donde cada panelista expositor o participante pudo hacer su aporte, al igual que en revistas prestigiosas como la del Poder Judicial de Perú, cuyos artículos son leídos por calificados integrantes del poder estadual, originando en estos inquietudes o 
toma de decisiones que podrían llevarnos a alguna solución de los problemas planteados.

Otra propuesta para proteger los valores de la sociedad cibernética, es la de generar políticas que alienten a las empresas vinculadas con la informática y las comunicaciones a que participen y colaboren en la protección de datos y obtengan con ello beneficios impositivos, o económicos, de igual forma las empresas de seguridad para que asesoren sobre los derechos, técnicas, y posibilidades de proteger los datos, tanto los existentes en el ordenador del usuario como los existentes en los bancos de datos, protegiendo el derecho a la intimidad del ser humano, y el valor económico que puedan representar los datos almacenados en los bancos legítimamente constituidos.

Sería para el infrascripto un gran logro, si el presente artículo, pudiera ser considerado como un aporte para la solución de la problemática planteada o con alguna incidencia para el logro de una concientización de la imprescindible necesidad de aprovechar todos los recursos existentes, en forma integral y articulada, y aprovechado por la humanidad para la consolidación de sus valores éticosociales, aportando argumentos para la obtención de normas estaduales o internacionales, que permitan combatir la impunidad de quienes aprovechando los efectos extraterritoriales de la transmisión de datos, obtienen beneficios ilegítimos, o logren burlar el castigo de los eventuales ilícitos cometidos en estas circunstancias.

A no dudar, el fortalecimiento de la protección de los datos, arrojaría un saldo altamente positivo ya que la intimidad no podría ser vulnerada con la facilidad con que se produce en estos momentos, como así también la protección económica de los valores, que la información procesada representa [...].

\section{CONCLUSIONES}

Que la información, sometida a un proceso de ordenamiento, en una computadora, genera un valor adicional a su propio contenido que denominamos data o dato.

La información en sí misma fue importante desde el principio de los tiempos, pero cuando analizamos la información procesada con tecnología cibernética (hardware y software adecuados) y comunicacional (telemática) su valor se multiplica geométricamente, a tal punto que se convierte en un paradigma principal de la sociedad cibernética. 
El procesamiento de la información, permite su acumulación, y se denomina bancos a aquellos lugares donde se conservan.

El fenomenal avance tecnológico, permite a esos bancos, guardar completísima información, que también puede ser cotejada y calificada.

Las sociedades van regulando la forma de concretar estos procedimientos, sin embargo, hay quienes pueden sortear las regulaciones, y destinar la información a fines para los cuales no fue autorizada su acumulación.

La posibilidad de trasmitir la información fuera de la soberanía del Estado en que se halle acumulada, puede generar la impunidad de quien se aproveche sin derecho a ello. También la velocidad en que pueden concretarse estos hechos, corre a favor del que actúa ilícitamente.

Los argumentos precedentes, ponen de manifiesto la necesidad de controlar estas conductas disvaliosas.

Para intentar el control debemos preguntarnos: $1^{\circ}$ ¿Qué elementos tenemos para lograr el fin deseado? $2^{\circ}$ ¿Cómo aprovechar los que resulten disponibles? $3^{\circ}$ ¿Quienes podrían realizar tan colosal tarea?

Al respecto podemos señalar, que debido al fenómeno de la inmediatez y de la extraterritorialidad propia de la transmisión de datos en la sociedad cibernética, los mecanismos de control no están preparados para dar respuestas inmediatas. Lo que significa que tendremos un largo camino que recorrer para obtener algún logro.

Lo positivo es que con la identificación del problema, la búsqueda de soluciones posibles se convierte en un imperativo categórico, pudiendo la tecnología ser utilizada para la obtención de soluciones, mediante la adecuada investigación y capacitación de los recursos disponibles.

Por ello, colijo que es necesario un proceso de concientización global, con especial énfasis en la capacitación técnica y ética que aliente a los gobiernos del orbe a concensuar y coordinar los esfuerzos, para que los objetivos éticos y morales de la sociedad cibernética no se desvirtúen y por el contrario se proyecten con la fuerza necesaria para combatir el uso indebido o delictivo de la informacion (data).

Algunas herramientas adecuadas para semejante tarea, sería la búsqueda de acuerdos globales, donde se puntualice la forma de cooperación de cada uno 
de los Estados intervinientes para la persecución de aquellos que utilizan indebidamente o delictivamente los datos informáticos.

Estos acuerdos deberían tener una rápida incorporación al ordenamiento vigente de los Estados, y una estructura multinacional que les sirva de apoyo y coordinación en temas de competencia y armonización legislativa.

Estos organismos multilaterales, tendrían a su cargo, señalar qué Estados no actúan con la celeridad necesaria o aquellos que por su inactividad culposa o dolosa son aprovechados por delincuentes o mal vivientes para operar desde allí, perjudicando a sujetos de la comunidad internacional, aprovechando la inactividad en tal sentido del Estado en que se cobija, lo que inevitablemente producirá mayores daños a la intimidad del ser humano y perjudicará patrimonialmente a quienes siendo legítimos tenedores de datos, vean que los mismos son ultrajados por terceros.

Como corolario final, puede afirmarse, que proteger la intimidad de las personas, defender el buen uso de los datos concentrados en bancos autorizados, evitar la comisión de ilícitos con el tráfico de datos, es una tarea en la que debemos participar todos los miembros de la sociedad cibernética, y buscar la forma de capacitar a aquellos que por falta de conocimiento han quedado excluidos, como así también buscar la capacitación de nuestros representantes en la sociedad, para que afronten esta realidad, con perspectiva universal, con la finalidad de llegar a un consenso, previo análisis y valuación de todas las propuestas.

Finalizo enfatizando que este humilde trabajo tuvo desde su inicio, la motivación, que pudiera ser un pequeñísimo aporte en tal sentido, pero aporte al fin. 